\title{
Ueber Werther's Methode der Analyse von Pulverrückständen.
} Diese Methode*) besteht bekanntlich darin, dass die Lösung des Schwefelkalium, kohlensaures Kali und unterschwefligsaures Kali enthaltenden Rückstandes zuerst mit kohlensaurem Cadmiumoxyd digerirt wird, wobei Schwefelcadmium entsteht und die äquivalente Menge kohlensauren Kalis in Lösung geht. Das Filtrat wird mit salpetersaurem Silberoxyd gefällt und das Gemenge von kohlensaurem Silberoxyd und Schwefelsilber durch Ammon getrennt, wobei ersteres Salz in Lösung geht und durch Salzsäure gefällt wird. Daraus ergibt sich die Menge des kohlensauren Kalis, wenn die dem Schwefelcadmium entsprechende in Rechnung gebracht wird. N. Fedorow ${ }^{* *}$ ) macht num darauf aufmerksam, dass die Grundlage dieses Verfahrens eine irrige sei, da beim Fällen des unterschwefligsauren Salzes mit Silberlösung Säure frei werde, welche eine bestimmte Menge des kohlensauren Silberoxyds wieder zersetzen müsse, weshalb es um so auffallender sei, dass $\mathrm{Karoly} \mathrm{i}^{* * *}$ ), als er nach diesem Verfahren, sowie nach dem von Bunsen (Fällen mit Manganchlorür) vergleichende Analysen von Pulverrückständen ausführte, übereinstimmende Resultate erhalten habe. Der Verf. selbst fand bei der Analyse eines solchen Rückstandes, der 21,3 pC. unterschwefligsaures Kali enthielt, nach dem Verfahren von Werther 20, nach dem von Bunsen 39,3 pC. kohlensaures Kali. Diese Differenz entspricht mehr als einem Aquivalent, was Verf. dadurch erklärt, dass das kohlensaure Silberoxyd leicht Kohlensäure verliere und das frei werdende Silberoxyd etwas in Wasser löslich sei.

Zur Bestimmung des Eisens im Gusseisen. C. M ène $\dagger$ ) warnt vor dem Versuche das Eisen im Gusseisen in der Weise bestimmen zu wollen, dass man dessen Lösung in Säuren direct mit übermangansaurem Kali titrirt, weil sich häufig in der Lösung Kohlenwasserstoff (d'hydrates de carbone) in -solcher Menge vorfinden, dass das mangansaure Salz in anormalen Mengen zersetzt werde: Es sei deshalb bei derartigen Analysen stets erforderlich dịe Lösung einzudampfen und im Rückstande jede organische Substanz durch Glühen zu zerstören.

Zur Analyse der Legirungen von Gold und Kupfer. Aus der Lösung der Chlorverbindungen der genannten Metalle fällt Oxalsäure neben

\footnotetext{
*) Journ. f. prakt. Chem. Bd. 55. p. 22.

*) Zeitschr. f. Chem. [NF] Bd. 5. p. 16.

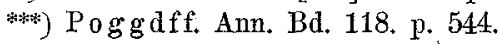

†) Compt. rend, Bd. 68, p. 449 .
} 